Caligrama, Belo Horizonte, v.20, n.1, p. 5-16, 2015

\title{
Prefácios e posfácios na primeira tradução e última retradução para 0 italiano de Lo cunto de li cunti de Giambattista Basile
}

\author{
Forewords and afterwords in the first translation \\ and last retranslation from Giambattista Basile's \\ Lo cunto de li cunti into Italian
}

Andréia Guerini

Universidade Federal de Santa Catarina (UFSC), Florianópolis, Santa Catarina, Brasil. andreia.guerini@gmail.com

Rozalir Burigo Coan

Universidade Federal de Santa Catarina (UFSC), Florianópolis, Santa Catarina, Brasil. rosalirb@yahoo.com.br

Resumo: Se as traduções mantêm vivos os "originais", as retraduções os colocam em contínuo movimento literário, abrindo espaço para algumas reflexões, com destaque para a posição do tradutor em relação à obra que irá traduzir. Neste artigo buscamos analisar alguns paratextos, mais especificamente os prefácios e posfácios, que orientaram a primeira tradução para o italiano do dialeto napolitano de Lo cunto de li cunti, de Giambattista Basile, realizada por Benedetto Croce, em 1925, e a sua última retradução, de Carolina Stromboli, em 2013, a fim de verificar o que norteou os dois projetos tradutórios e ver em que medida eles se diferenciam.

Palavras-chave: literatura italiana; Basile; Lo cunto de li cunti; tradução; retradução; paratexto.

Abstract: While translations keep "original" texts alive retranslations provide them with unbroken literary flowing - opening up spaces for further reflections and putting the translator's position vis-à-vis the work to be translated in the spotlight. Within this article we aimed at analysing some paratexts - more specifically fore and afterwords - 
which have guided the first translation of the Neapolitan dialect present in Giambattista Basile's Lo cunto de li cunti into Italian, carried out by Benedetto Croce in 1925, and the last retranslation promoted by Carolina Stromboli, in 2013, as to verify how the translation projects' foundation has been established and in which sense they differ from one another.

Keywords: Italian literature; Basile; Lo Cunto de li cunti; translation; retranslation; paratexts.

Recebido em 13 de janeiro de 2015

Aprovado em 19 de abril de 2015

\section{Introdução ${ }^{1}$}

A tradução pensada por Antoine Berman como experiência do outro (2013, p. 23), como ato dialético, fornece argumentos para a elaboração de um conceito de crítica fundado no fato de que é necessário um conhecimento histórico das obras literárias. A relação dos textos com a história coloca a língua em movimento. Para Albanese é a própria incompletude da linguagem que estabelece nesse processo um "continuo e vitale divenire" (ALBANESE, 2012, p. 40).

Uma análoga ideia de tradução, vista como processo provisório, é a de Mattioli. Para ele, a tradução é experiência dinâmica, um contínuo e atualizado diálogo com a história. Nas suas palavras:

Imparare a convivere con la provisiorità non è una rinuncia, ma una conquista, significa infatti riconoscere alla traduzione una partecipazione profonda e una funzione nell'ambito della vita dell'arte e aprirsi ad una comprensione non pregiudicata di questa attività, la cui centralità è fortemente presente nella coscienza culturale del nostro tempo tanto da configurarsi come punto di riferimento per il riassestamento dei saperi. La riflessione sulla tradizione traduttiva è un compito importante della cultura contemporanea, scoprire come l'altro è stato ascoltato, come è risuonata la voce degli antichi nel corso

\footnotetext{
${ }^{1}$ Este artigo apresenta parte da pesquisa de tese de doutorado intitulada Os paratextos nas (re)traduções de Lo cunto de li cunti de Giambattista Basile ao italiano: prefácios e pósfácios.
} 
dei secoli è importante anche per capire l'altro nel nostro tempo, la distanza temporale e quella spaziale sono gli assi lungo i quali la differenza si inserisce nel processo traduttivo (MATTIOLI, 2001, p. 39).

A temporalidade, a dimensão histórica, que continuamente atualiza a linguagem e as traduções, permanece um ponto central nas reflexões dos críticos da tradução. Aliás, é o próprio tempo histórico, enquanto processo incompleto, a dar continuidade, não de forma sequencial, mas fazendo emergir em cada retradução, a incontestável tarefa do tradutor.

Em Pour une critique des traductions: John Donne (1995), Berman sinaliza a necessidade de se estudar a posição do tradutor e de se percorrer a sua poética, pois,

Tout traducteur entretient un rapport spécifique avec sa propre activité, c'est-à-dire à une certaine conception ou perception du traduire, de son sens, de ses finalités, de ses formes et modes. Conception et perception qui ne sont pas purement personnelles, puisque le traducteur est effectivement marqué par tout un discours historique, social, littéraire, idéologique sur la traduction (et l'écriture littéraire) (BERMAN, 1995, p. 74).

Para o teórico francês, "toute traduction conséquente est portée par un projet, ou visée articulée” (1995, p. 76). É o mesmo que reconhecer a necessidade de um prévio conhecimento da obra a ser traduzida, de modo que o tradutor, com base em seu projeto, pode determinar, a priori, o grau de autonomia e heteronomia que será direcionado para a sua tradução, a partir das exigências particulares do texto. Toda tradução, então, deve ser submetida a um projeto, e se consolidará mediante a aplicação e a constatação desse projeto; este só será específico e acessível a partir da própria tradução. Segundo Berman,

[...] tout ce qu'un traducteur peut dire et écrire à propos de son projet n'a réalité que dans la traduction. Et cependant, la traduction n'est jamais que la réalisation du projet: elle va où la mène le projet, et jusqu'où la mène le projet (BERMAN, 1995, p. 77).

Para o teórico francês, "les formes d'un projet de traduction, lorsqu'il est énoncé, sont multiples” (BERMAN, 1995, p. 77). Portanto, o tradutor pode organizar seu projeto tendo em mente uma edição 
monolíngue ou bilíngue; pode apresentar uma edição com ou sem paratextos; pode optar por uma edição que leve o leitor até o texto, ou o seu contrário; pode incluir no seu projeto o autor e a sua obra, e justificar a sua tradução; pode ainda mencionar uma possível influência de outras traduções, no caso de uma retradução etc.

Ao tomar como base esses pressupostos, o objetivo deste artigo é analisar os prefácios e posfácios da primeira tradução do dialeto napolitano de Lo cunto de li cunti de Giambattista Basile para o italiano, realizada por Benedetto Croce, em 1925, e a sua última retradução realizada por Carolina Stromboli, em 2013, a fim de verificar o que norteou os dois projetos tradutórios, e ver em que medida eles se diferenciam.

\section{Lo cunto de li cunti, overo lo trattenemiento de'peccerille, de Basile: a obra e suas traduções para o italiano}

O napolitano Giambattista Basile (1575-1632) viveu à moda dos literatos da sua época, prestando serviços militares e administrativos às cortes. Nesse ambiente, ele escreveu odes, canções, poemas laudatórios em italiano e espanhol. Depois inventou para si um nome, Gian Alessio Abbatuis, e um novo jeito de fazer literatura, escrevendo em dialeto napolitano: Lettere, Muse napolitane e Lo cunto de li cunti, overo lo trattenemiento de 'peccerille, todas publicadas postumamente.

Lo cunto de li cunti, overo lo trattenemiento de peccerille, publicado entre 1634-1636, é uma coletânea de cinquenta histórias, contadas num arco de cinco dias, dez a cada dia (por isso o título póstumo de Pentamerone $^{2}$ ), reunindo histórias da tradição popular napolitana, que "non si potevano ben dire se non in dialetto [...]" (CROCE, 1943, p. 228).

Com Lo cunto, Basile deixa para as sucessivas gerações o protótipo de um novo gênero literário (RAK, 2004, p. 14) que, apesar do seu tortuoso percurso, chega até nós confinado na literatura infantil, sob a forma de "conto de fadas", "conto maravilhoso". Em suas páginas, reconhecemos as histórias de Cinderela, de $A$ bela adormecida, e ainda nos familiarizamos com um gato falante, à espera de calçar as botas em outra corte, com crianças abandonadas nos bosques, animais falantes, ogros, fadas, príncipes e princesas que se movem em um tempo indeterminado, obrigados, incessantemente, a se expressarem na engenhosidade da poética barroca.

\footnotetext{
${ }^{2}$ Este título não foi dado pelo autor. Ele aparece pela primeira vez em 1674, em uma edição organizada por Pompeo Sarnelli, e é bastante recorrente entre a crítica.
} 
Lo cunto de li cunti teve várias edições em dialeto napolitano nos séculos XVII e XVIII, e antes da tradução de Croce para o italiano, ele já havia sido traduzido para o alemão, inglês e francês, apresentando-se como uma importante coletânea de histórias que influenciou os estudos sobre esse gênero na Europa, tendo interlocutores como Charles Perrault e os irmãos Grimm.

A primeira tradução integral para o italiano de Lo cunto de li cunti é realizada por Benedetto Croce. O filósofo está convencido de que somente dessa forma a obra poderia circular facilmente entre os leitores e, assim, ocupar seu lugar na literatura nacional. Não por acaso, Italo Calvino diz que é impossível fazer qualquer discurso sobre Basile sem partir de Croce, pois "è d'un libro di Basile-Croce che sto parlando, perché non conosco il primo autore se non attraverso il secondo" (CALVINO, 1996, p. 129).

A gênese dessa tradução integral é explicitada por Croce em uma correspondência, de 25 de outubro de 1924, ao editor Giovanni Laterza, na qual diz:

[...] ho cominciato ad attuare il pensiero venutomi quest'estate di una traduzione italiana del Cunto de li cunti, libro meraviglioso, tradotto in lingue straniere e anche in dialetto bolognese, ma che gl'italiani non conosco perché scritto in vecchio e difficile dialetto napolitano. La traduzione mi sta riuscendo benissimo, e alcune novelle che ho letto agli amici e alle mie bambine hanno avuto gran sucesso. Sospendo dunque gli altri miei lavori, e mi do tutto a questo, e spero di compierlo in 3 mesi (CROCE, 2006, p. 212).

Com muita expectativa o livro é publicado em 1925, em dois volumes, reunindo 657 páginas, com o título de Il Pentamerone ossia la fiaba delle fiabe. O primeiro volume traz a primeira e a segunda jornadas; o segundo, a terceira, quarta e quinta jornadas. Nas páginas internas constam uma foto do autor, a repetição da página de rosto e uma dedicatória a Fausto Nicolini, em que ele se refere ao amigo "come a uno dei pochi che ancora amano le opere della vecchia letteratura dialettale napoletana" (CROCE, 1925, p. 7). Um prefácio do tradutor, em forma de "Discorso", intitulado "Giambattista Basile e l'elaborazione artistica delle fiabe popolari", abre as portas para o texto e deixa visível o trabalho do tradutor, não apenas por esse prefácio, mas também pelas inúmeras notas de rodapé que acompanham o texto. No segundo volume, ainda na instância paratextual, consta a repetição da página de rosto, conforme 
o primeiro volume, seguida das respectivas jornadas. Ao final de cada volume, um índice traz, sumariamente, os títulos das histórias.

Por um período de cinquenta anos, isto é, até a edição crítica de Petrini, de 1976, que reúne as três obras de Basile escritas em dialeto: Le muse napolitane, Lettere e Lo cunto de li cunti, a divulgação do texto basiliano foi mediada por Croce. Nos anos seguintes, foram realizadas quatro traduções completas do dialeto napolitano para o italiano: a de Michele Rak, em 1986; a de Ruggero Guarini, em 1994; a de Roberto De Simone, em 2002. Em 2013, é publicada em Roma, pela Editora Salerno, a mais recente retradução italiana da obra, feita por Carolina Stromboli, com o título Lo cunto de li cunti overo lo trattenemiento de peccerille. Esta tradução integra a coleção I novellieri italiani, dirigida por Enrico Malato, que tem como proposta oferecer uma documentação, tanto quanto possível, do desenvolvimento da novelística italiana, do século XIV ao século XX. A tradução é publicada em dois volumes e vem acompanhada de uma edição crítica do texto napolitano, organizada pela tradutora. Cada volume está envolvido por uma mesma sobrecapa, onde se lê o nome e o pseudônimo do autor, o título e o subtítulo, o nome da tradutora, o símbolo e o nome da editora, seguindo o padrão da coleção.

O primeiro prefácio é de Malato, o qual destaca o fato de ainda não ter sido feita uma edição crítica que atendesse às precisas exigências da obra de Basile. Ele entende que com essa edição crítica Carolina Stromboli disponibiliza aos leitores um texto rigorosamente reconstituído, acompanhado de uma pontual tradução literária (grifos nossos), de modo a proporcionar ao leitor o deleite de uma leitura curiosa, amparada por um número expressivo de notas (MALATO, 2013, p. XIV). O segundo prefácio é o da própria tradutora, em que ela situa o autor e a obra no contexto da literatura napolitana do século XVII; discorre sobre a estrutura da obra e discute, sobretudo, o topos de uma "língua inventada", rótulo frequentemente atribuído pela crítica ao texto de Basile (STROMBOLI, 2013, p. XXVIII). Croce, por exemplo, fala de uma linguagem "maccheronica" (1911, p. 69); Michele Rak, de uma "lingua letteraria morta" (1986, p. 1040) e Roberto De Simone caracteriza-a como um dialeto "del tutto inventato" (2002, orelha do segundo volume).

Stromboli dedica boa parte do seu discurso prefacial à discussão em torno do dialeto usado por Basile, que segundo ela, é muito diferente do atual e até mesmo daquele documentado nos textos dos séculos anteriores, 
mesmo que, com o tempo, tenham permanecidos alguns traços. O foco no estilo e na prosa de Basile antecipa e, ao mesmo tempo, justifica a sua iniciativa de uma nova edição e a consequente tradução da obra. Stromboli reconhece que a tradução de Croce tornou conhecido Basile e a sua obra, mas a difusão, o acolhimento e a receptividade da sua tradução esconderam o texto original. Na sequência dos dois prefácios, aparecem notas biobibliográficas sobre Basile. O segundo volume dessa edição de Stromboli traz, nas páginas finais, um posfácio da tradutora, em que ela apresenta a trajetória editorial da obra, com os critérios adotados para a preparação dessa nova edição crítica, e o seu projeto de tradução, seguidos dos índices, conforme recomendação da editora.

\section{Paratextos: prefácios e posfácios na primeira tradução e última retra- dução para o italiano de Lo cunto de li cunti de Giambattista Basile}

Após essas informações sobre as edições da obra de Basile para o sistema literário italiano, passemos agora a analisar especificamente o prefácio da primeira tradução de Lo cunto de li cunti de Giambattista Basile para o italiano, realizada por Benedetto Croce, em 1925, e os dois prefácios e um posfácio que fazem parte da sua última retradução, realizada por Carolina Stromboli, em 2013.

Ao organizar e definir sistematicamente os discursos que acompanham a publicação de uma obra literária, Genette apresenta o paratexto como sendo "aquilo por meio de que um texto se torna livro e se propõe como tal a seus leitores, e de maneira mais geral ao seu público". Trata-se, segundo ele, de uma

[...] zona de transição e [...] de transação: lugar privilegiado de uma pragmática e de uma estratégia, de uma ação sobre o público, a serviço, bem ou mal compreendido e acabado, de uma melhor acolhida do texto e de uma leitura mais pertinente - mais pertinente, entenda-se, aos olhos do autor e de seus aliados" (GENETTE, 2009, p. 9-10).

O paratexto, segundo o estudioso francês, divide-se em peritexto $e$ epitexto. O peritexto trata das mensagens que se situam ao redor do texto, no espaço do mesmo volume; o epitexto abraça tudo o que está "ainda 
em torno do texto, mas a uma distância mais respeitosa [...] em geral num suporte midiático [...] ou sob a forma de comunicação privada" (2009, p. 12). O texto, portanto, vem sempre acompanhado de certo número de

[...] produções verbais ou não, como um nome de autor, um título, um prefácio, ilustrações, que nunca sabemos se devemos ou não considerar parte dele, mas que em todo caso o cercam e o prolongam, exatamente para apresentá-lo, no sentido habitual do verbo, mas também em seu sentido mais forte: para torná-lo presente, para garantir sua presença no mundo, sua recepção e seu consumo, sob a forma, pelo menos hoje, de um livro (GENETTE, 2009, p. 9).

Desses paratextos, o prefácio é “toda espécie de texto limiar (preliminar ou pós-liminar), autoral ou alógrafo, que consiste num discurso produzido a propósito do texto que segue ou que antecede", e o posfácio, que é "considerado uma variedade de prefácio" (GENETTE, 2009, p. 145) guiarão, como já informado, a análise pretendida neste artigo.

O tradutor, quando autor de um prefácio ou posfácio, tem a possibilidade de estar dentro e fora do texto, como um agente a instigar critérios que guiam a crítica literária; critérios esses, não mais voltados para a busca de valores, mas para a análise das funções que concorreram para a criação de um novo texto literário.

Quando a atividade do tradutor é também a de prefaciador, o seu discurso pode ter uma ligação direta com o ato de traduzir, porque ele não apresenta somente o autor da obra, mas também o seu próprio trabalho, suas escolhas, retomando, assim, certos traços do prefácio autógrafo, segundo a tipologia de Genette, mas com o foco no ato de traduzir. Nesse sentido, Genette afirma que "em caso de tradução, o prefácio pode ser [...] assinado pelo tradutor." O tradutor-prefaciador pode, eventualmente, comentar, entre outras coisas, a sua própria tradução (GENETTE, 2009, p. 233).

O prefácio de Croce à sua tradução é um resumo de seus estudos sobre a obra de Basile, "ripreso per essa dal giovanile affetto" (CROCE, 1925, p. XXIX), que foram publicados em seus Saggi sulla letteratura italiana del Seicento, em 1911, em Storia dell'età baroca in Italia, em 1929, e em Nuovi saggi sulla letteratura italiana del Seicento, em 1931. Nesse discurso, o filósofo apresenta uma pequena biografia do autor, segundo ele, um "gentiluomo", cuja trajetória literária se inicia com odes e outras composições laudatórias, em italiano, enquanto prestava serviço 
militar aos nobres; mas dessas composições pouco se tem notícia. Basile é reconhecido pelos seus escritos em dialeto napolitano, principalmente por sua obra mais importante: Lo cunto de li cunti, "un libro vivo e non ha che vedere con una mera raccolta di fiabe [...] come se ne hanno ora tante" (CROCE, 1925, p. XIX), cujos personagens se movem ao ritmo da poética barroca. Croce também informa ao leitor sobre o seu método de tradução e antecipa dizendo que Basile "era un litterato aulico, un studioso di lingua e di stile [...] e in italiano mentalmente concepiva, e poi traduceva in dialetto per vaghezza dell'insueto e per sfoggiare la ricchezza del sermone partenopeo" (1925, p. XXX). Desse modo, acrescenta o filósofo, traduzir para o italiano a sua obra não é tanto darlhe uma nova veste, quanto manter sua originalidade (1925, p. XXX). Ele informa também que traduziu Lo cunti de li cunti da raríssima edição original, de 1634-36, que se encontra na Biblioteca Nazionale de Turim, seguindo alguns princípios:

a) Manteve-se fiel às palavras do texto procurando não reduzi-las, mas confessa que transitou com plena libertada pela sintaxe que, em Basile, algumas vezes, é péssima e defeituosa;

b) Resistiu à tentação de substituir, por equivalência, as expressões idiomáticas, vocábulos e frases de uso corrente na língua italiana;

c) Procurou manter não só os ornamentos barrocos, como também um certo sabor napolitano;

d) Acrescentou notas que possam esclarecer indicações e alusões a coisas e costumes daquela época, e, assim, mostrar ao leitor, além das histórias, os aspectos da realidade histórica que Basile tinha em sua imaginação (CROCE, 1925, p. XXX).

Como se pode observar, os termos "fidelidade", "liberdade" e "equivalência" estão na base do seu projeto tradutório. Diante dessa proposta, percebemos em Croce um tradutor "visível", aparentemente buscando uma "via di mezzo" na sua tradução. Nesse caso, pode-se dizer que ele caminhou ao lado do autor, no espaço literário, trabalhando o texto com a inadvertida "intenção" de cruzar os limites da sua teoria da intraduzibilidade, pois como explica Emilio Mattioli:

La dificoltà che sorge da questi testi è quella della coerenza con le affermazioni recise sull'intraducibilità che troviamo nelle opere teoriche; se è possibile che in 
una traduzione "risuoni la voce del poeta o si trasmetta parte alcuna delle vibrazioni dell'originale" evidentemente la poesia è traducibile e non nei suoi elementi prosastici soltanto. Io credo che la contraddizione nasca dal fatto che Croce di fronte al problema concreto del tradurre era inavvertitamente spinto a varcare i limiti della sua teoria [...] (MATTIOLI, 1983, p. 138).

Não encontramos, portanto, um Croce detrator do princípio da intraduzibilidade, conforme propõe em sua teoria, mas um tradutor atento, que buscou explicitar o seu horizonte poético e tradutório, fazendo-o de modo convincente e conveniente em seu texto prefacial, que compreende 24 páginas. Vale destacar que a maior parte dessas páginas é destinada à apresentação do autor e de sua obra, restando apenas o penúltimo parágrafo para expor o seu projeto de tradução.

Das formulações de Croce passemos às de Stromboli, que ao final do segundo volume, em "Nota al Testo", repassa ao leitor a trajetória das primeiras edições de Lo Cunto de li cunti, desde a sua primeira publicação, em 1634-36; informa também os critérios adotados por ela para a edição crítica do texto napolitano, que acompanha a sua tradução. Do seu limitado discurso de acompanhamento, contendo 15 páginas, ela dedica apenas a última página à revelação dos critérios que nortearam sua tradução:

a) Facilitar a leitura do texto napolitano;

b) Respeitar a prosa de Basile quanto à sintaxe e ao estilo;

c) Usar notas explicativas;

d) Buscar para as locuções idiomáticas e proverbiais um correspondente em italiano, baseado no princípio da "semelhança" (STROMBOLI, 2013, p. 1012).

Pelo conteúdo do seu projeto de tradução vimos que Stromboli parece ter um horizonte semelhante ao de Croce, ou seja: facilitar a leitura do texto, respeitar a prosa de Basile, usar notas explicativas. Além disso, percebemos que tanto Croce quanto Stromboli optam por meios que levam o leitor até o autor e o trazem de volta, até o ponto em que fica estabelecido o princípio da interpretação. Para chegar até esse ponto, adotam um projeto de tradução que não apaga o texto de partida, ao contrário, por vias e métodos diferentes, informam ao leitor que ele está lendo um texto traduzido. O significativo número de notas de rodapé em suas respectivas traduções também contribui para isso. 


\section{Conclusão}

Bruno Osimo fala do tradutor como "ponte", e se ele é uma ponte entre dois sistemas da "semiosfera", e à sua mediação incide os que não têm a capacidade individual de percepção para passar, automaticamente, de um mundo a outro, "bisogna vedere fino a quale punto del ponte il lettore viene condotto per mano dal traduttore, e fino a che punto è il mondo altro a essere semplificato e addomesticato in modo a apparire più vicino"(OSIMO, 2011, p. 103). É aqui que a mediação do tradutor se explica: de um lado, fornece ao leitor instrumentos para lidar com um texto inacessível; de outro, torna "compreensível" o texto, operação que parece descrever os projetos tradutórios de Croce e Stromboli.

Nesse sentido, percebemos que o horizonte tradutório incide na parte medial da "ponte", e ali os tradutores apresentam aos leitores o que conseguiram recolher do que estava retido, e às vezes oculto, nas camadas não imediatamente visíveis do texto a ser traduzido, segundo um princípio que vai além da "fidelidade" e da "lealdade". Percebemos também que Croce e Stromboli parecem ter procurado tornar o texto "compreensível" ao leitor de outra língua, pois tentaram evidenciar aspectos do texto de partida e do texto de chegada em seus escritos paratextuais.

Vale sublinhar ainda que, embora as traduções sejam datadas, elas precisam ser renovadas, pois a língua muda, o leitor muda, de modo que a tradução também muda, mesmo quando a primeira tradução foi realizada por um tradutor do porte de Croce. Aliás, as diferentes retraduções da obra de Basile confirmam que as diferentes traduções de uma mesma obra, nesse caso a do Lo cunto de li Cunti, faz com que o leitor possa ter uma melhor compreensão do rico e denso texto produzido por Basile no século XVII. Não por acaso, Berman diz que "toda tradução é solicitada a envelhecer, e é o destino de todas as traduções dos clássicos da literatura universal serem, cedo ou tarde, retraduzidas" (BERMAN, 2002, p. 315). E assim, com suas diferentes traduções, essa obra de Basile, Lo cunto de li cunti, vem confirmando a sua vitalidade no sistema literário italiano e europeu.

\section{Bibliografia}

ALBANESE, A. Metamorfosi del Cunto di Basile. Traduzioni, riscritture, adattamenti. Ravena: Longo, 2012.

BASILE, G. Il Pentamerone assia la Fiaba delle fiabe.Tradução de Benedetto Croce. Bari: Laterza, 1925. 
BASILE, G. Lo cunto de li cunti, overo lo trattenemiento de peccerille. Tradução de Carolina Stromboli. Roma: Salerno, 2013.

BERMAN, A. A tradução e a letra, ou o Albergue do longínquo. Tradução de Marie Hélène Catherine Tores. Mauri Furlan e Andréia Guerini. 2. ed. Florianópolis: Copiart/PGET, 2013.

BERMAN, A. A prova do estrangeiro. Tradução de Maria Emília Pereira Chanut. Bauru-SP: EDUSC, 2002.

BERMAN, A. Pour une critique des traductions: John Donne. Paris: Gallimard, 1995.

CALVINO, I. Sulla fiaba. Milano: Mondadori, 1996.

CROCE, B. Saggi sulla letteratura italiana del seicento. Bari: Laterza, 1911.

CROCE, B. Giambattista Basile e l'elaborazione artistica delle fiabe popolare. Bari: Laterza, 1925.

CROCE, B. Uomini e cose della vecchia Italia. 2. ed. Bari: Laterza, 1943.

CROCE, B. Carteggio III. 1921-1930. Bari: Laterza, 2006.

GENETTE, G. Paratextos editoriais. Tradução de Álvaro Faleiros. São Paulo: Ateliê Editorial, 2009.

MALATO, E. Prefácio. In: BASILE, Giambattista. Lo cunto de li cunti, lo trattenemiento de'Peccerille. Tradução de Carolina Stromboli. Roma: Salerno, 2013.

MATTIOLI, E. Studi di poetica e retorica. Modena: Muchi, 1983.

MATTIOLI, E. Ritmo e traduzione. Modena: Mucchi, 2001.

OSIMO, B. Il manuale del traduttore. 3. ed. Milano: Hoepli, 2011.

RAK, M. Il sistema dei racconti nel Cunto de li cunti di Basile. In: PICONE, Michelangelo; MESSERLI, Alfredo. Giovan Battista Basile e l'invenzione della fiaba. Ravena: Longo, 2004.

STROMBOLI, C. Prefácio. In: BASILE, G. Lo cunto de li cunti, overo lo trattenemiento de peccerille. Tradução de Carolina Stromboli. Roma: Salerno, 2013. 